\title{
Vacinas e campanhas: as imagens de uma história a ser contada
}

\section{Vaccines and campaigns: images with a story to tell}

Ângela Pôrto

Carlos Fidelis Ponte

\author{
Pesquisadores da Casa de Oswaldo Cruz \\ Av. Brasil, 4365 \\ 21045-900 Rio de Janeiro - RJ Brasil \\ aporto@coc.fiocruz.br ponte@coc.fiocruz.br
}

PORTO, A. e PONTE, C. F.: 'Vacinas e campanhas: imagens de uma história a ser contada'. História, Ciências, Saúde - Manguinbos, vol. 10 (suplemento 2): 725-42, 2003.

A iconografia em torno das vacinas e das campanhas de vacinação constitui importante acervo para aqueles que se interessam pela temática das políticas de imunização. Nela, muitas vezes, estão presentes diversas representações sobre as vacinas e as doenças por elas combatidas; os ambientes onde as vacinações eram postas em prática; os veículos e as estratégias de convencimento e comunicação de massa, bem como o conhecimento que se tinha a respeito das doenças e das vacinas utilizadas para combatê-las.

Neste número selecionamos duas coleções de imagens que julgamos importantes para a compreensão da história das políticas de imunização em nosso país. Referimo-nos ao material reunido pela exposição A Revolta da Vacina: da varíola às campanhas de imunização e ao trabalho de Ângela Porto sobre a erradicação da poliomielite no Brasil, onde são analisadas as mudanças ocorridas nas campanhas publicitárias convocando a população a vacinar seus filhos.

PALAVRAS-CHAVES: iconografia; vacinas; campanhas de vacinação; poliomielite; Revolta da Varíola.

PORTO, A. and PONTE, C. F.: 'Vaccines and campaigns: images with a story to tell'. História, Ciências, Saúde — Manguinhos, vol. 10 (supplement 2): 725-42, 2003.

The iconography on vaccines and vaccination campaigns is of great value to those interested in the subject. Especially noteworthy are the representations depicting vaccines and the diseases they are meant to fight, the surroundings where vaccination takes place, the media and strategies used to convince the public, and what used to be known about these diseases and the vaccines employed to combat them.

This issue of our journal offers readers a glimpse into two collections that have much to contribute towards an understanding of the bistory of immunization policy in Brazil: material from the exhibit A Revolta da Vacina: da variola às campanhas de imunizacão (The Vaccine Rebellion: from smallpox to immunization campaigns), inaugurated in 1994, and material on the eradication of polio in Brazil, based on the 1995 exhibit Um Mundo sem Pólio (A world without polio). The article includes an analysis of changes in ad campaigns that encourage the public to vaccinate children.

KEYWORDS: iconography, vaccine, vaccination campaign, polio, Smallpox Rebellion. 
$\mathrm{E}$ ntre os instrumentos de política de saúde pública, a vacina ocupa, por certo, um lugar de destaque. No Brasil, as estratégias de vacinação têm alcançado altos índices de eficiência e servido de parâmetro para iniciativas semelhantes em outros países. Exemplos como os das campanhas contra a varíola e a poliomielite, bem como a proximidade da erradicação do sarampo em nosso território, demonstram os bons resultados dos programas de cobertura vacinal coordenados pelo Ministério da Saúde.

No entanto, apesar de seu sucesso, grande parte dos registros dessa história encontra-se sob o risco da perda, impossibilitando um melhor aproveitamento da experiência brasileira neste campo. Tal fato deve-se, entre outras razões, à ausência no âmbito da administração pública, de uma política efetiva de arquivos que oriente e estimule a preservação criteriosa de acervos e a sistematização de informações, propiciando a perda de registros relevantes e agravando os problemas decorrentes do elevado grau de dispersão das fontes primárias disponíveis sobre o tema.

Esta realidade pode ser verificada quando da realização, em 1994, da pesquisa que serviu de base para a montagem da exposição A Revolta da vacina: da varíola às campanhas de imunização. ${ }^{1}$ Naquela oportunidade constatou-se a precariedade dos arquivos do ministério da Saúde, em Brasília, e da Superintendência de Campanhas de Saúde Pública (Sucam), no Rio de Janeiro, onde esperávamos encontrar textos e imagens relativos às políticas e às campanhas de vacinação no país.

Parte dessa lacuna pode ser sanada graças ao trabalho desenvolvido pela equipe encarregada do levantamento de fontes para a exposição que localizou, no próprio Ministério e em outras instituições e arquivos de personalidades envolvidas com a temática da mostra, informações importantes sobre a trajetória das políticas governamentais nesta área.

Por ocasião da pesquisa para a realização da exposição Um Mundo sem pólio, em 1995, verificou-se fenômeno inverso. Naquela data comemorava-se um ano da erradicação do poliovírus selvagem das Américas. A equipe de pesquisa localizou uma série de cartazes da campanha contra a poliomielite, de vários anos e localidades diferentes. Tal diversidade chamou nossa atenção e muitos desses cartazes compuseram painéis da referida exposição. Depois da mostra, o material foi devolvido para as instituições de origem que, no entanto, não tiveram a preocupação de preservá-los.

De lá para cá muita coisa mudou, e atualmente o Ministério da Saúde conta com uma boa equipe de arquivistas e documentalistas que têm contribuído para minorar os problemas constatados durante os anos 1990. Por outro lado, o trabalho da Casa de Oswaldo Cruz nesta área prosseguiu, por meio de iniciativas como a elaboração do

\footnotetext{
1 A exposição teve como curadores Ana Palma, Carlos Fidelis da Ponte e Pedro Paulo Soares, que compõem o quadro de profissionais da Casa de Oswaldo Cruz.
} 
livro Febre amarela, a doença e a vacina: uma história inacabada e a realização dos projetos A História da Poliomielite: seu controle e sua erradicação no Brasil e Políticas públicas de imunização no Brasil na $2^{\underline{a}}$ metade do Século XX, ambos apoiados pelo Programa Estratégico de Pesquisas da própria instituição. Espera-se que, apesar dos problemas ainda observados neste campo, tais iniciativas sejam capazes de resgatar e preservar grande parte dos registros desta história.

A seguir, apresentamos uma pequena parte do material iconográfico produzido em quase um século de história. Nesta seleção privilegiamos, em virtude da importância que adquiriram na história da saúde pública, as estratégias de combate a duas doenças: a varíola e a poliomielite. O material utilizado faz parte da exposição A Revolta da Vacina: da Varíola às campanhas de imunização e do trabalho produzido por Ângela Porto sobre a campanha de erradicação da poliomielite.

\section{A Revolta da Vacina: da varíola às campanhas de imunização}

Inaugurada em 1994, a exposição A Revolta da Vacina: da varíola às campanhas de imunização traça as trajetórias das políticas de imunizações implementadas pelo Brasil ao longo do último século. Tendo como ponto de partida o episódio que marcou a reação popular à lei da vacinação obrigatória proposta por Oswaldo Cruz, a mostra busca atualizar a temática da vacinação enfocando aspectos relativos às campanhas de erradicação da varíola e da poliomielite, aos programas de imunizações implementados por organismos internacionais e pelo país, bem como aqueles relativos à pesquisa e desenvolvimento de novas vacinas.

Utilizando diferentes formas de linguagem, tais como vídeos, painéis fotográficos, cenários, ambientação sonora e uma representação teatral especialmente concebida para o evento, a exposição foi considerada inovadora sob o ponto de vista estético, sem comprometer a seriedade do tema, abordado com didatismo e concisão.

Prevista inicialmente para ser exibida somente no Rio de Janeiro, a exposição tornou-se itinerante e, desde então, vem percorrendo vários estados do Brasil. Atualmente seu conteúdo esta sendo revisto e ampliado tendo por objetivo a sua participação no leque de eventos e produtos que marcarão os cem anos da revolta ocorrida no Rio de Janeiro, em novembro de 1904.

Pensada para superar o caráter efêmero do evento alusivo à revolta, a exposição possibilitou a localização e o recolhimento de acervos importantes relacionados às políticas de imunização implementadas pelo Estado brasileiro e por organismos internacionais ao longo do século XX. Entre este acervos destacam-se aqueles relativos às campanhas de erradicação da varíola no Brasil e no mundo e da 
campanha de erradicação da poliomielite no país encontrados com o dr. Cláudio Amaral, último presidente da Campanha de Erradicação da Varíola e ex-secretário de Saúde do estado do Rio de Janeiro.

Em novembro de 2004, completam-se os cem anos da eclosão da Revolta da Vacina. Para marcar a data está prevista a realização de uma série de eventos e produtos, entre os quais se incluem mostras de vídeo, seminários, lançamentos de livros e a reedição da exposição revista e ampliada. Nesta seção serão apresentadas algumas fotografias, charges e caricaturas que integram a mostra.

\section{A vacina e a vacinação como objetos de estudo}

Considerada como um dos maiores levantes populares ocorridos no Brasil durante o século XX, a Revolta da Vacina tem sido, muitas vezes, interpretada como um movimento originário, quase que exclusivamente, de manipulações políticas engendradas por segmentos da elite brasileira descontentes com os rumos assumidos pela República. Nesta perspectiva, a insurreição seria fruto da pregação de opositores do regime que viram na insatisfação popular contra Oswaldo Cruz e Pereira Passos, responsáveis respectivamente pelo combate às epidemias e pela reforma urbana que então se processavam, uma oportunidade de derrubar o governo liderado por Rodrigues Alves. Amálgama de diferentes interesses, a oposição reunia grupos diversificados e muitas vezes antagônicos entre si. Integravam as hostes antigovernistas militares ligados a Floriano Peixoto; intelectuais do apostolado positivista; republicanos radicais; monarquistas e parcelas da população afetadas pelo "bota abaixo", nome pelo qual ficou conhecida a política de reorganização do espaço urbano empreendida pelo prefeito do Distrito Federal, Pereira Passos.

Entretanto, em que pese a ação destes grupos, não há como negar que a obrigatoriedade da vacinação por si só trazia força suficiente para provocar reações violentas em defesa da privacidade e da livre determinação. Rui Barbosa, um dos que discordavam da obrigatoriedade, argumentava:

Não tem nome, na categoria dos crimes do poder, a temeridade, a violência, a tirania a que ele se aventura, expondo-se, voluntariamente, obstinadamente, a me envenenar, com a introdução no meu sangue, de um vírus sobre cuja influência existem os mais bem fundados receios de que seja condutor da moléstia ou da morte (apud Sevcenko, 1993).

Na realidade, o episódio da Revolta da Vacina reúne uma série de elementos bastante significativos no que concerne ao complexo fenômeno que envolve a vacina e sua utilização social. Tais elementos são muitas vezes negligenciados, sendo totalmente ignorados ou 
colocados em segundo plano. Chalhoub (1996, p. 99) alerta-nos, por exemplo, que mesmo na historiografia mais recente,

os populares sempre reagem — 'resistem' —, nunca 'agem', isto é, nunca se sabe exatamente que tipo de experiência histórica, de formas de entender o mundo e a sua situação de vida poderiam informar positivamente o movimento de luta contra a vacinação. Além disso, há aqui uma visão monolítica e generalizante, tanto deste universo popular quanto daquele projeto mais geral de aburguesamento da sociedade carioca.

Este mesmo autor argumenta ainda que alguns estudiosos da revolta têm resolvido os problemas decorrentes da falta de informação de forma simples. Na visão de Chalhoub (idem, p. 101), "como o assunto permanece em grande medida desconhecido, chega-se à conclusão de que a vacina foi um simples pretexto para uma revolta que tinha motivos outros e mais relevantes".

Na verdade, uma série de outros fatores contribuíram para a eclosão da revolta, entre os quais se incluem a prepotência das autoridades e os conflitos entre visões de mundo bastante distintas. Para Chalhoub (idem, p. 134), por exemplo, "é difícil prosseguir na investigação das atitudes da população ... . em relação à vacina sem enfrentar em certa medida o problema das concepções afro-brasileiras sobre a doença e a cura".

Longe de ser apenas um movimento propiciado por disputas entre as elites, a revolta é um evento emblemático. Trata-se de um momento altamente significativo para todos aqueles que trabalham com saúde pública. Lá estão presentes aspectos que não podem ser ignorados pelas autoridades sanitárias e por historiadores interessados na temática das vacinas e das campanhas de vacinação.

É preciso compreender que a vacinação é um objeto de difícil apreensão, constituindo-se, na realidade, em um fenômeno de grande complexidade onde se associam e se entrechocam crenças e concepções políticas, científicas e culturais as mais variadas. De fato, longe de ser um ato isolado, sujeito apenas aos parâmetros de aferição e decisão da medicina ou das ciências biomédicas, a vacinação é também, pelas implicações socioculturais e morais que envolve, a resultante de processos históricos nos quais são tecidas múltiplas interações e onde concorrem representações antagônicas sobre o direito coletivo e o direito individual, sobre as relações entre Estado, sociedade, indivíduos, empresas e países, sobre o direito à informação, sobre a ética e principalmente sobre a vida e a morte. Potencialmente polêmica, a vacina e seus usos contemplam ainda interesses geopolíticos e macroeconômicos, tendo sido ultimamente associada a conflitos entre nações e ao bioterrorismo.

Objeto multifacetado sujeito a inúmeras influências, a utilização social de vacinas requer para a compreensão de suas diversas 
implicações atenção sobre uma grande gama de fatores. Estão em jogo não só a vacina selecionada para estudo, mas também a conjuntura em que ela é empregada; as estratégias e os métodos de vacinação escolhidos; as faixas populacionais a serem atingidas e os meios e as formas de comunicação de massa adotados.

Cabe investigar ainda as formas de apresentação e de aplicação do produto utilizadas e os resultados daí derivados, uma vez que, como se sabe, a opção entre lancetas, seringas, pistolas ou gotas são não somente determinadas por diversos condicionantes, mas também determinantes de uma série de outros. De fato, o advento da pistola, por exemplo, apesar dos problemas de contaminação posteriormente observados, propiciou uma maior rapidez e facilidade no processo de vacinação, dotando as campanhas onde foi empregada de maior agilidade e possibilidade de execução de seus objetivos. Do mesmo modo, a vacina oral facilitou a adesão de voluntários nos dias nacionais de vacinação contra a poliomielite, contribuindo, inclusive, para a erradicação da doença em nosso território.

Nas páginas seguintes são apresentados alguns exemplos de imagens que integram a mostra. São charges, caricaturas e fotografias que retratam momentos distintos da história das políticas de imunizações implementadas no país ao longo do século XX. Organizadas em ordem cronológica, as imagens percorrem a ambiência que antecede os acontecimentos de novembro de 1904, passando pela revolta e suas conseqüências, para chegar à campanha de erradicação da varíola em fins dos anos 1970 e começo dos 1970.

Carlos Fidelis Ponte

\section{REFERÊNCIAS BIBLIOGRÁFICAS}

Chalhoub, Sidney 1996

Sevcenko, Nicolau 1993
Cidade febril: cortiços e epidemias na corte imperial. São Paulo, Companhia das Letras.

A Revolta da Vacina: mentes insanas em corpos rebeldes. Scipione, São Paulo. 


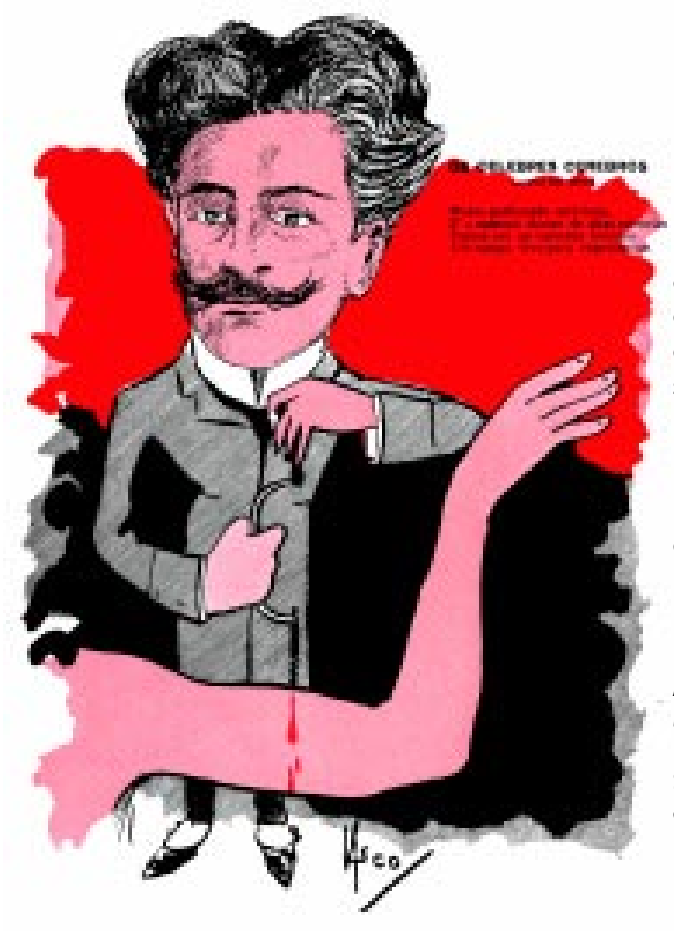

Na charge publicada em Avenida, de 3 de setembro de 1904, Vasco critica a atuação de Oswaldo Cruz, que ainda foi alvo de versos sarcásticos.

'Os célebres cérebros'

“Nessa perfuração arteriana, É o másculo doutor de altas ciências Parece ver na natureza humana Um campo vivo para experiências" Em E. de C. Falcão (org.), Oswaldo Cruz Monumenta Histórica: a incompreensão de uma época. Oswaldo Cruz e a caricatura. Brasiliensia Documenta, vol. VI, tomo 1, São Paulo, Acervo da biblioteca da Casa de Oswaldo Cruz.1971.

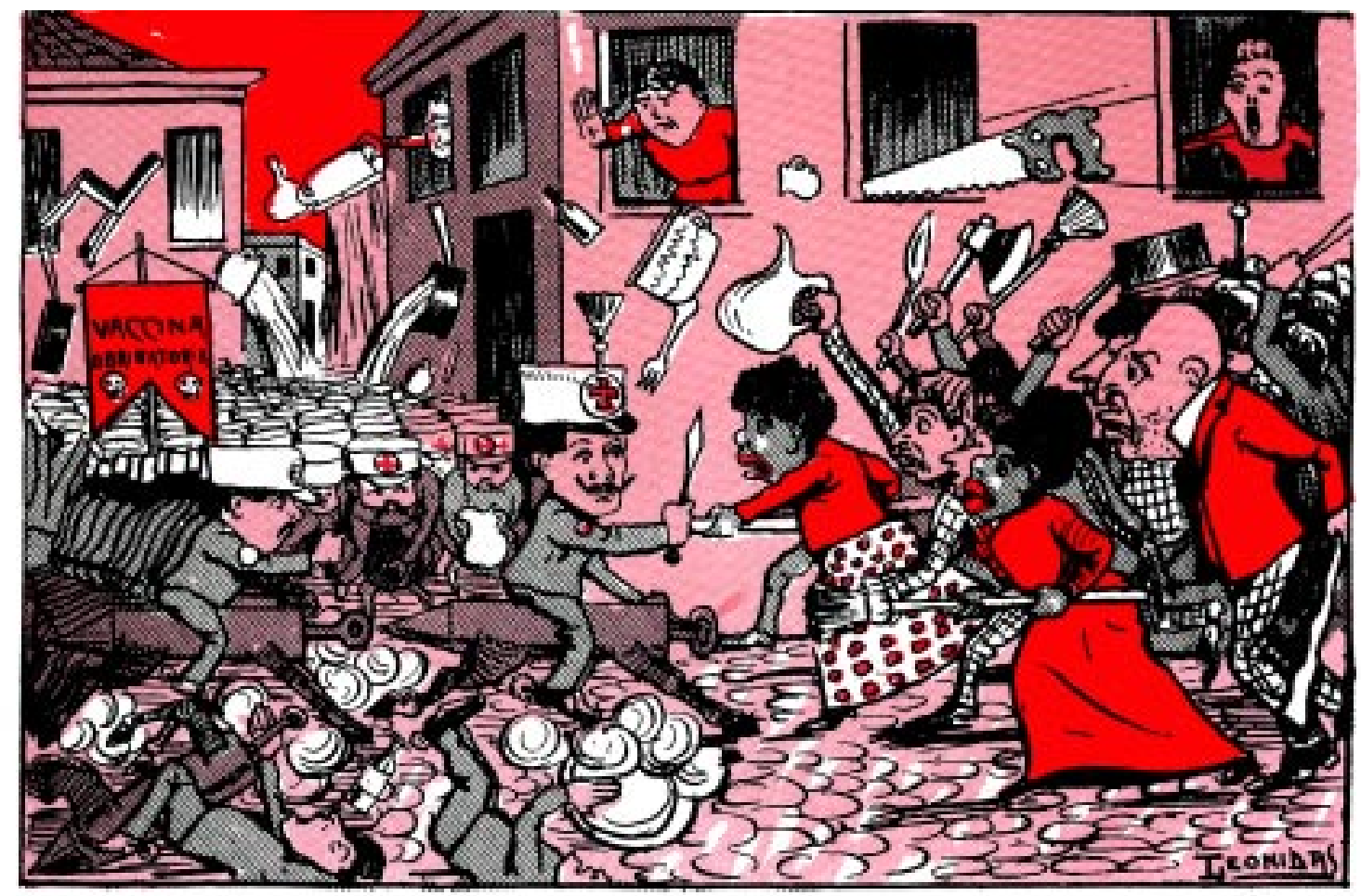

No desenho de Leônidas, publicado na revista O Malho de 29 de outubro de 1904, a legenda reproduzida a seguir antecipava a Revolta da Vacina, que viria a ocorrer dias depois, entre 12 e 15 de novembro, quando a população enfrentou Oswaldo Cruz e sua guarda: “Espetáculo para breve nas ruas desta cidade. Oswaldo Cruz, o Napoleão da seringa e lanceta, à frente das suas forças obrigatórias, será recebido e manifestado com denodo pela população. O interessante dos combates deixará a perder de vista o das batalhas de flores e o da guerra russojaponesa. E veremos no fim da festa quem será o vacinador à força !....”

Em E. de C. Falcão (org.), Oswaldo Cruz Monumenta Histórica: a incompreensão de uma época. Oswaldo Cruz e a caricatura. Brasiliensia Documenta, vol. VI, tomo 1, São Paulo, Acervo da biblioteca da Casa de Oswaldo Cruz.1971. 
Diferentes das charges que retratam o período em que ocorreu a Revolta da Vacina, as fotos das campanhas de vacinação da segunda metade do século $X X$ ressaltam a mobilização popular e a adesão aos programas de imunização do Ministério da Saúde. Nas fotos, exemplos de mobilização durante a campanha de erradicação da varíola nos anos 1960.
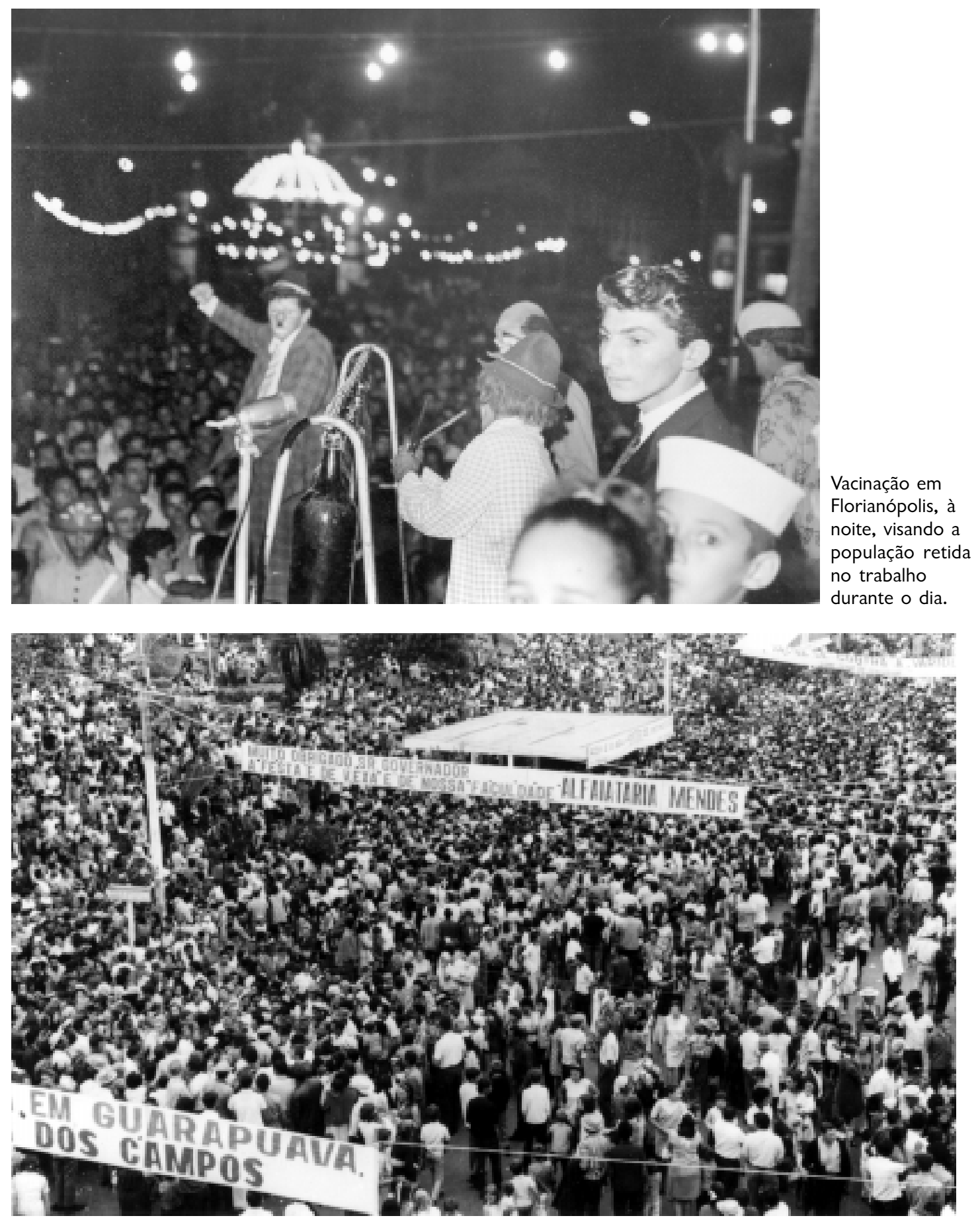

Em grandes eventos, a campanha de vacinação reunia multidões em busca da vacina. 
A vacinação de autoridades e personalidades queridas e respeitadas pela população abriu caminho e facilitou o trabalho de vacinadores durante a campanha de erradicação da varíola.

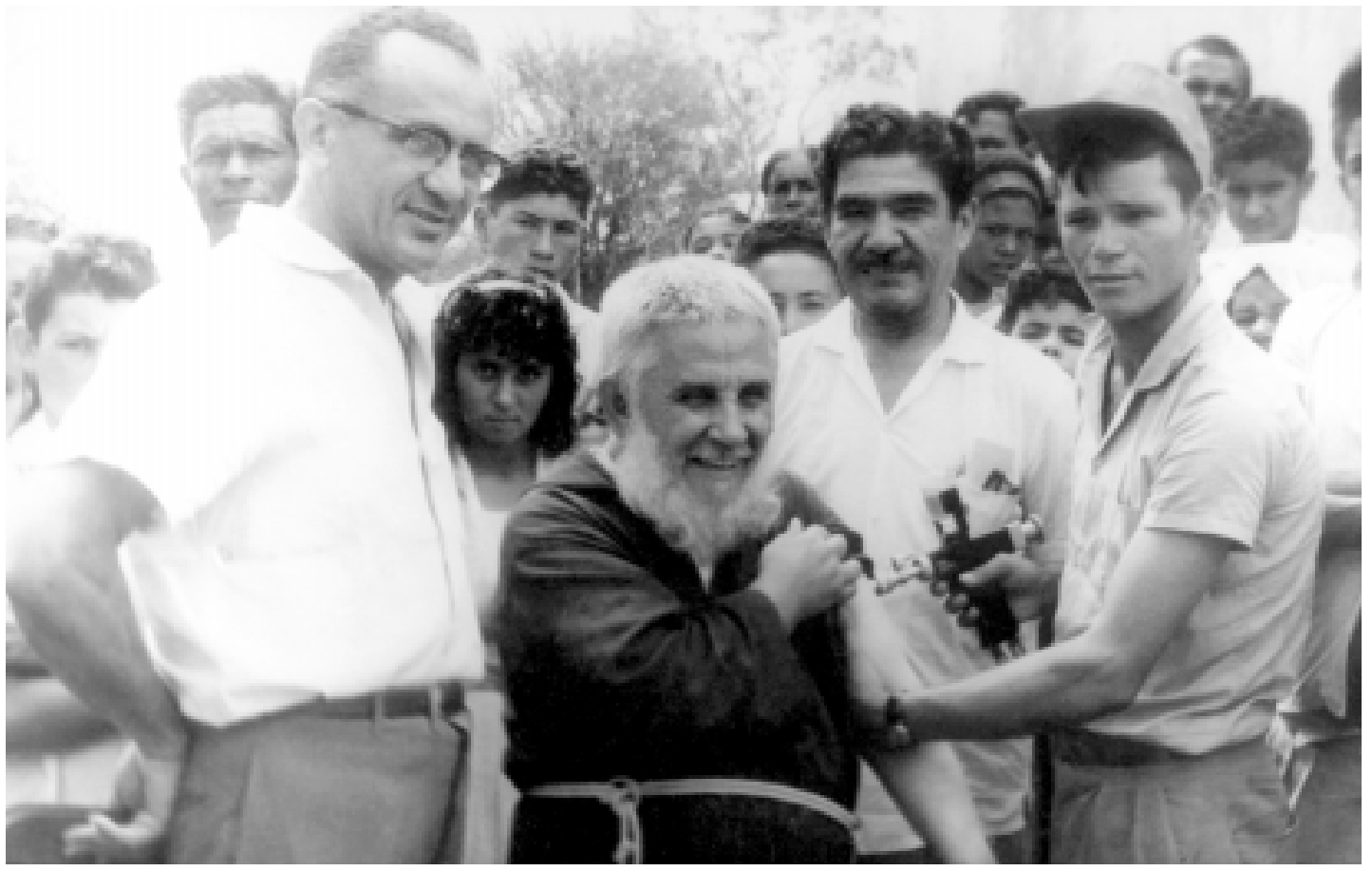

Considerado como santo por muitos nordestinos, Frei Damião participou da estratégia de convencimento da população, comparecendo à vacinação. (Paraíba, década de 1960).
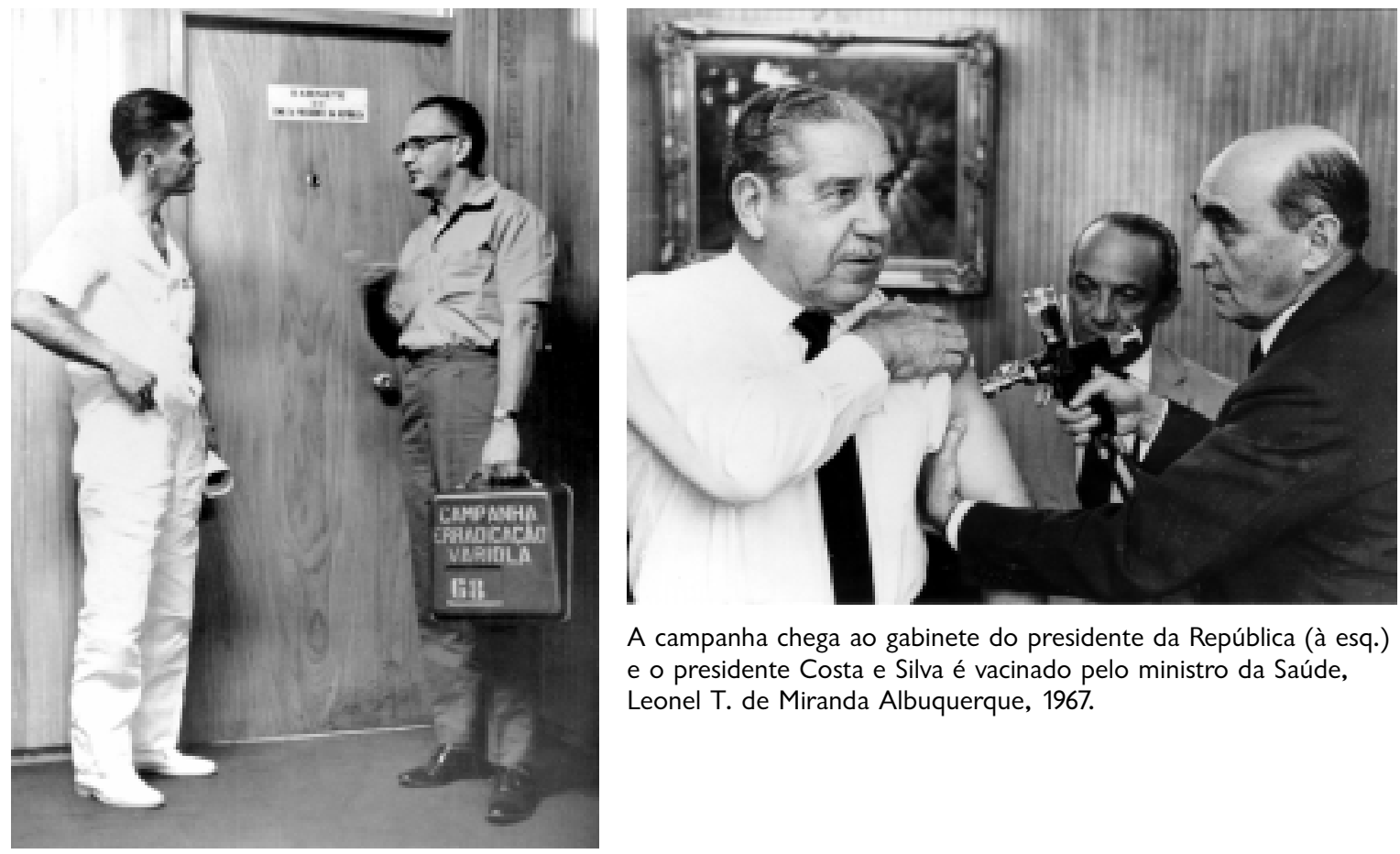

A campanha chega ao gabinete do presidente da República (à esq.) e o presidente Costa e Silva é vacinado pelo ministro da Saúde, Leonel T. de Miranda Albuquerque, 1967. 

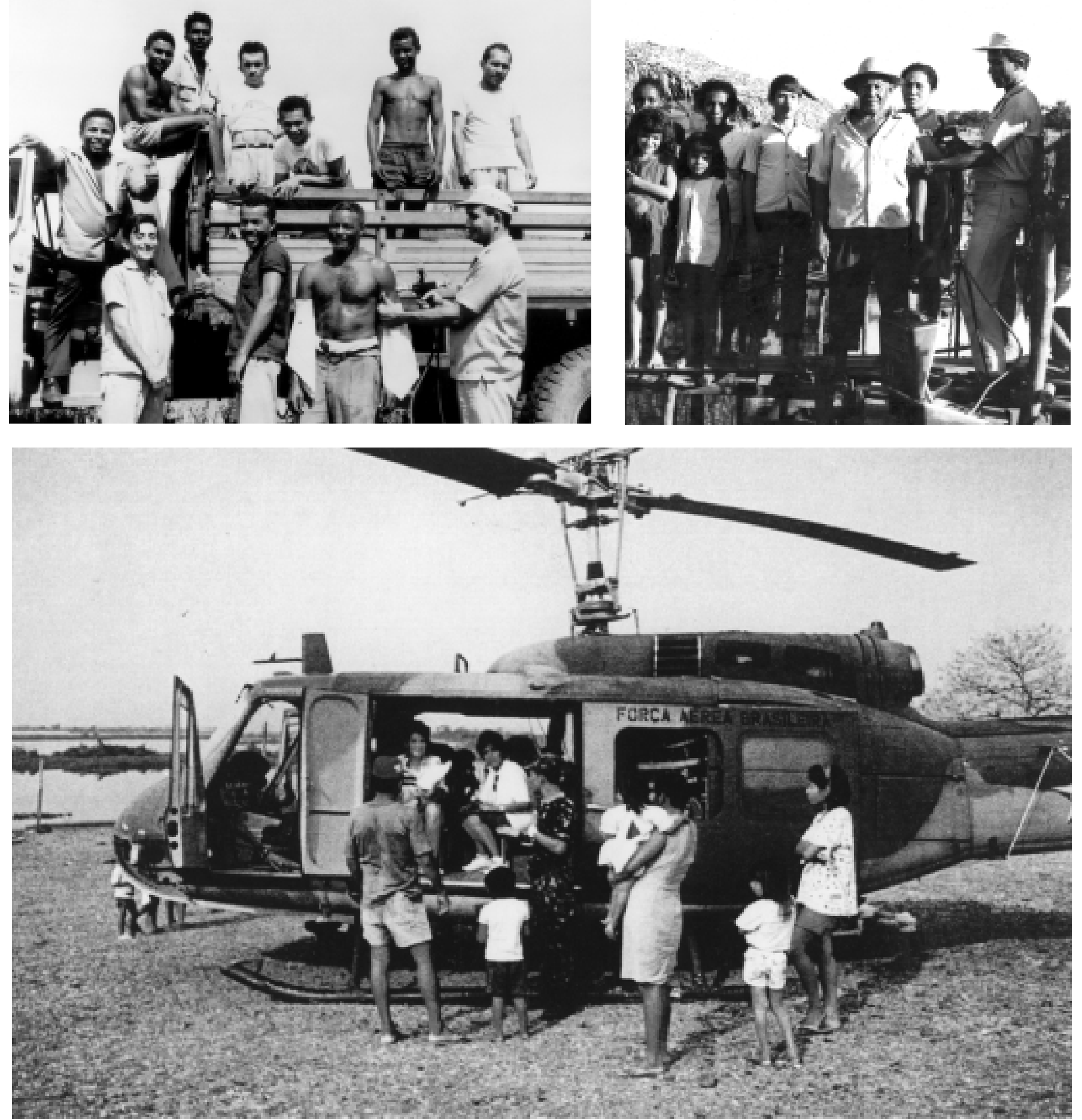

A ação dos vacinadores nos lugares mais pobres e remotos do país passou a ser constantemente divulgada pelas campanhas de vacinação. Vacinação nas palafitas das cidades nordestinas (alto á direita), nas estradas do interior do país (alto á esq.) e em lugares onde o acesso só é possível de barco ou helicóptero. 


\section{Cartazes da campanha de erradicação da poliomielite: reflexões sobre o discurso gráfico}

Transmitir a informação é algo vital para a gestão da saúde. E a capacidade de entendimento da mensagem por diferentes públicos é essencial para se alcançar os resultados desejados. O Ministério da Saúde utiliza sofisticados meios de comunicação para a criação, produção e veiculação da informação. No entanto, como órgão da área de saúde, tem necessidade de desenvolver "projetos especiais, porque trabalha diretamente com as questões limítrofes do ser humano, com as marcas que o informam sobre a qualidade da sua vida, das suas doenças e da sua morte" (Weber apud Pitta, 1995, p. 152). Assim, qualquer definição de política de comunicação para implantar uma campanha de saúde pública depende de uma certa ousadia, pois estarão em debate questões como cidadania, miséria e riqueza, moral e ética, higiene etc.

Os órgãos de saúde ou entidades promotoras devem 'pensar' a comunicação de modo estratégico, pois a campanha publicitária será marcada por imagens ou linguagens consistentes, porém muitas vezes de abordagem delicada. As informações veiculadas têm de ser de fácil assimilação por toda a sociedade, por que, em geral, sua mensagem visa atingir a todos, e ser capaz de romper barreiras impostas pelo analfabetismo ou por singularidades regionais. Quem lida com a saúde deve desenvolver formas de comunicação eficazes, que informem e provoquem reações no público-alvo. Para tanto, geralmente são utilizadas as estratégias de sedução usuais ao marketing das campanhas que 'vendem' moda, alimentos, bebidas e cigarros. No entanto, temos que ter em vista que "a saúde é um campo conceitual marcado por cuidados e ética próprios" (idem, ibidem, p. 157). E isto também deve estabelecer os cuidados que se deve ter quando se pretende definir as estratégias de comunicação. É comum lançar mão do humor para promover a descontração, aplicado amplamente na campanha da Aids (Nascimento, 1997, pp. 169-84; Xavier, 2001, pp. 93-221). Em qualquer área, para se fazer uma campanha bem-sucedida de um produto, são necessários amplos estudos de avaliação de variáveis geográficas, culturais etc. O sucesso da campanha, como conseqüência, aumenta a credibilidade e a legitimidade da instituição promotora e do produto.

A comunicação de massa difundindo a importância de se vacinar contra várias doenças passou por uma série de inovações, sobretudo após o advento dos dias nacionais de vacinação contra a poliomielite, instituídos em 1980. Ainda na década de 1970, visando a incorporação de novos hábitos e práticas de saúde, o Ministério da Saúde fez ajustes 
de linguagem à população alvo em suas campanhas, aproximandose das comunidades e de outras realidades regionais. Os dias nacionais de vacinação adotaram como estratégia a produção de material informativo, como cartazes, folhetos e manuais, veiculados em diversos meios e divulgadores de sua linha de ação. Seu objetivo era despertar a consciência da população para a necessidade da vacina, em especial pais e responsáveis por crianças menores de cinco anos, mobilizar a sociedade em torno dessa questão e envolver outras entidades nesta tarefa. Essa estratégia é bem-sucedida e em 1985 a Organização PanAmericana de Saúde (OPAS) conclama todos os países das Américas a se engajarem na luta pela erradicação da poliomielite. A partir daí várias iniciativas são adotadas, entre elas a criação de uma logomarca para a campanha. Seu criador foi o artista plástico mineiro Darlan Rosa, então funcionário de um setor de publicidade de medicamentos do Ministério da Saúde, com especialidade em ilustrar rótulos, adequar a linguagem da saúde para o público leigo e produzir imagens que pudessem ser compreendidas por todos. Darlan calcou seu estudo na idéia de não se privar a criança do direito de andar. Inspirou-se nas séries de fotos de Eadweard Muybrigde que, em 1887, desenvolveu estudos sobre a locomoção, imprimindo movimento às fotos que mostravam em seqüência o caminhar de uma criança. No traço de Darlan, o corpo da criança evoluiu para duas gotas, representando as doses necessárias de vacina; e o seu caminhar acompanha o cronograma de compromisso do governo brasileiro em erradicar a poliomielite. A logomarca foi batizada com o nome de Zé Gotinha, a partir de um concurso, que contou com a participação de escolas públicas de todo o Brasil e tinha por objetivo popularizar o símbolo da campanha.

Em 1993, para comemorar os vinte anos do Programa Nacional de Imunizações (PNI), o Zé Gotinha virou a marca das campanhas de multivacinação. O personagem foi construído sobre o mito do herói, que triunfará contra todos os males, as doenças. Sua imagem foi fartamente utilizada em campanhas locais, assumindo as características das populações, como, por exemplo, em campanhas do Nordeste, em que Zé Gotinha aparece como cangaceiro.

O Ministério da Saúde continuou buscando novas metodologias e técnicas de aproximação com a população. Associou-se a grandes agências de publicidade, modernizando sua linguagem escrita e visual. Passou a fazer uso de figuras conhecidas no cenário nacional: atores, jogadores de futebol e cantores famosos, e mudou sua estratégia de comunicação com o público. O apelo inicial da campanha contra a pólio associava a doença ao terror, à culpa e ao medo. Os pais tinham exclusiva responsbilidade sobre o acontecimento da doença. As imagens veiculadas eram sempre de crianças usando aparelhos tutores nas pernas, muletas, ou cadeira de rodas, ou seja, traziam a marca de sua deficiência física e eram mostradas em situação de dependência. 
A criança, assim caracterizada, está associada à idéia de alguém que será sempre tutelado.

A estratégia de marketing utilizada, de atingir as pessoas mostrando a elas todo o horror da doença, revelava, no entanto, que não havia uma preocupação com os sentimentos dos já atingidos e, muito mais, revelava um grande preconceito em relação às pessoas portadoras de deficiência. A campanha tendia a chocar também os deficientes físicos, por estar demonstrando a menos-valia do seqüelado. A campanha com Ronaldinho e outros atletas passava a idéia de que os portadores de deficiência não podem ser campeões como ele. Na tevê chegou a ser veiculada uma chamada convocando para o Dia Nacional de Vacinação, mostrando Ronaldinho sentado numa cadeira de rodas e a legenda: "Imagine se ele poderia ser um campeão se não tivesse tomado a gotinha." Essa imagem provocou a ira dos portadores de paralisia infantil, que lutam diariamente para mostrar suas aptidões, para provar que são capazes frente ao mercado de trabalho, ou para desenvolver atividades ditas 'normais', para tudo ser colocado em questão em apenas três segundos de comercial. Fez também a indignação da deputada Tânia Rodrigues, paralítica por pólio e militante das causas em favor da melhoria da qualidade de vida dos deficientes físicos, que declarou: "Ora! Ninguém pensa com as pernas! Existem várias maneiras de um portador de deficiência física tornar-se campeão, inclusive agora com o incremento do desporto paraolímpico." ${ }^{1} \mathrm{De}$ acordo com a deputada, como desportista de proeminência, Ronaldinho não poderia participar de uma propaganda que menosprezava os esportes paraolímpicos. A deputada coloca-se firmemente contra qualquer tipo de mensagem que deprecie quem tem alguma deficiência. Também alerta para a necessidade de não se fazer somente investimentos na área de prevenção da doença, mas no reaparelhamento urbano, na facilitação dos acessos ao deficiente e, conseqüentemente, na melhoria de sua qualidade de vida.

Toda essa polêmica em torno da estratégia de marketing de chocar a população mostrando a seqüela da doença, e que não leva em consideração os atingidos por ela, provocou ligeiras mudanças, visíveis já nos cartazes de convocação para a $2^{a}$ dose da vacina. Passou-se a se utilizar crianças, sósias dos heróis nacionais, mostradas sem a marca da doença, mas trazendo ainda mensagem que desqualificava o portador de paralisia infantil, na medida em que alertava para a impossibilidade de sucesso, ou de "ser alguém na vida", no caso de a criança ser atingida pela pólio.

Essa polêmica continuaria evoluindo. Na campanha do ano seguinte, a imagem da criança não estava mais associada a um atleta de sucesso, mas a ênfase ainda era a mesma. Mas, se por um lado, ${ }^{1}$ Depoimento feito no Seminário 'Poliomielite: 40 Anos da Vacina Sabin', realizado em 12 de
dezembro de 2001, pelo projeto 'História da Poliomielite e de sua Erradicação no Brasil'. 
Trabalho realizado no âmbito do projeto História da Poliomielite e de sua Erradicação no Brasil, apresentado no XXII Simpósio Nacional da Anpuh/PB, no Simpósio no 25 : História das Idéias e das Práticas sobre Saúde e Doença. ainda se fazia uso do terror, por outro, já não se mostravam mais crianças usando esses aparelhos. Essas imagens foram substituídas pelo apelo à responsabilidade individual. Passou-se a falar em compromisso, no comprometimento da população convocada a participar, a comparecer aos postos.

Firmou-se a imagem de crianças saudáveis e havia toda uma preocupação em mostrar a diversidade étnica, passando a idéia de que isso é possível para todos, conforme a ideologia da campanha da Organização Mundial de Saúde (OMS) — Por um mundo sem pólio — visando erradicar a doença, e cuja meta era o ano 2000.

Hoje quase não se usam mais palavras, basta um sinal. O gesto da criança mostrando a língua e pedindo a gotinha supre a necessidade de produzir linguagem. E nem é preciso mais convocar os pais, a estratégia de marketing está voltada para a criança.

Ângela Pôrto

\section{REFERÊNCIAS BIBLIOGRÁFICAS}

Pitta Áurea da Rocha (org.)

1995

Nascimento, Dilene

Raimundo do

mar.-jun. 1997

Xavier, Caco

mar.-jun. 2001
Saúde E comunicação: visibilidades e silêncios. São Paulo, Hucitec/Abrasco.

'A face visível da Aids'. História, Ciências, Saúde-Manguinhos, vol. 4 (1).

'A Aids é coisa séria'. História, Ciências, Saúde-Manguinhos, vol. 8 (1). 


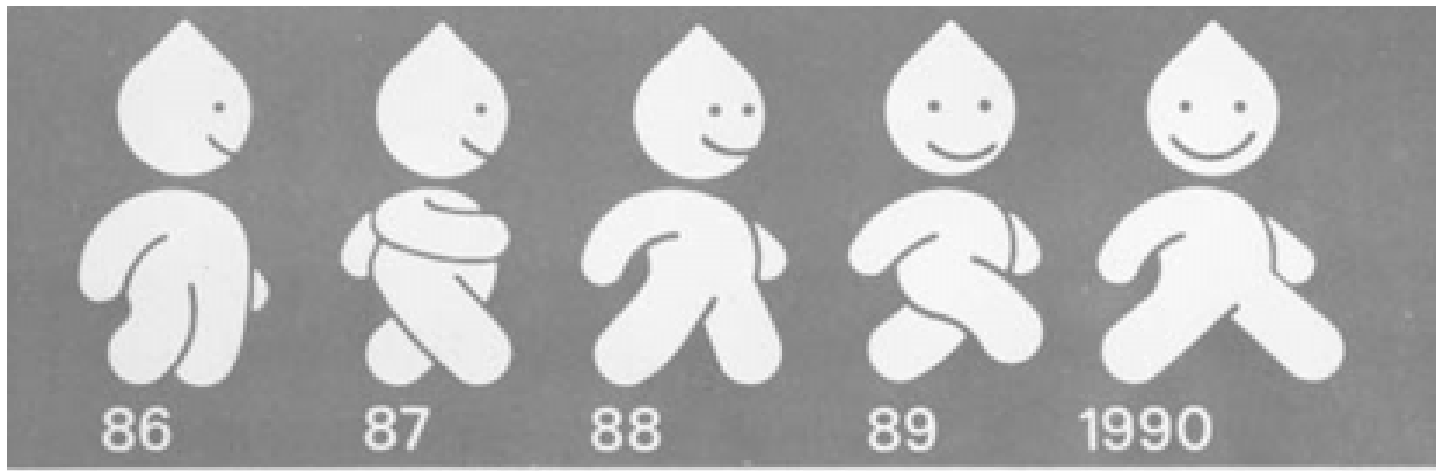

\section{ERRADICAÇÃO DA PARALISIA INFANTIL}

O nome 'Zé Gotinha' associa as idéias de brasileiro e vacina e hoje é sinônimo de vacinação. Esta marca teve várias utilizações na mídia: em desenho animado, cartilhas, cartazes de campanha, camisetas, anúncios de TV.

\section{Continuar a vacinar pra pólio não voltar}

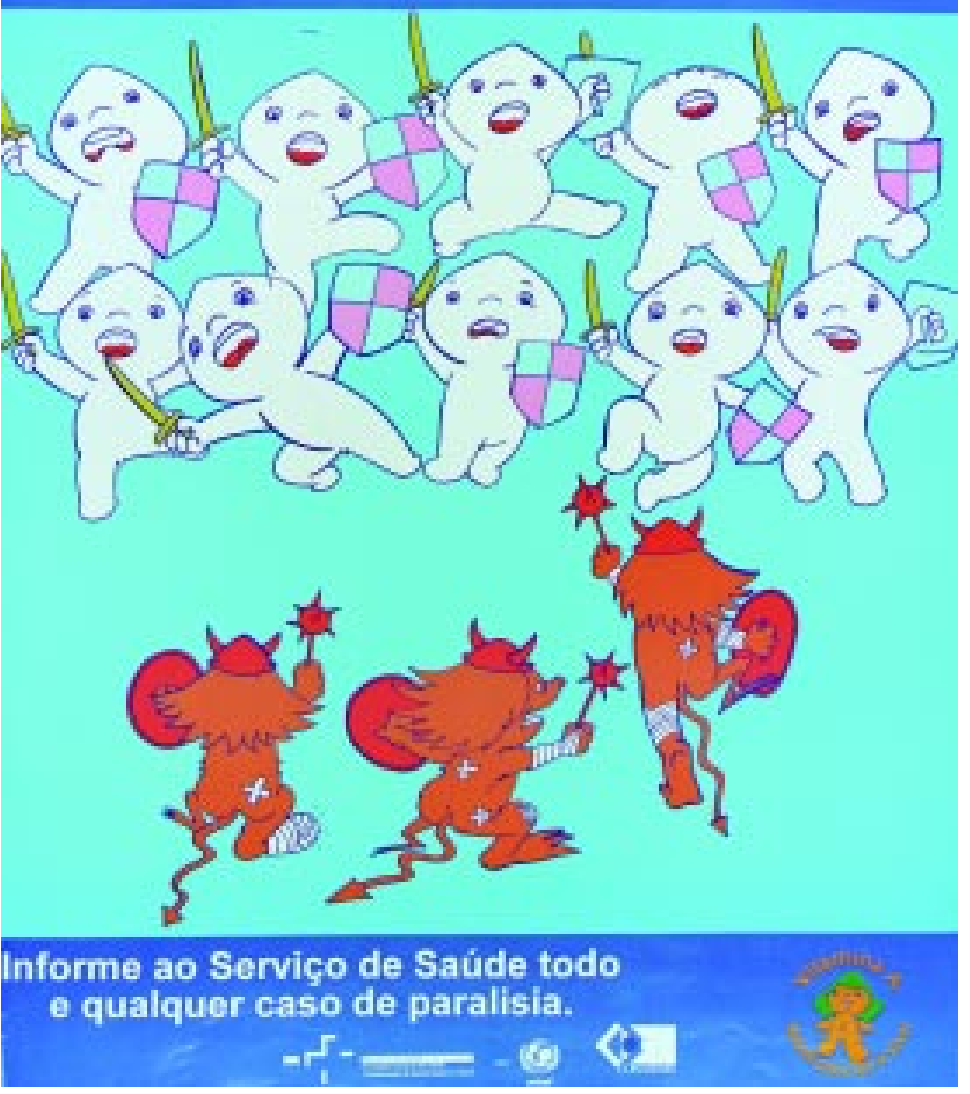

Neste cartaz, Zé Gotinha está caracterizado de cruzado lutando contra os bárbaros selvagens, os poliovírus. 
A criança traz a marca da deficiência física, olha o mundo através da janela e é caracterizada como incapaz de exercer qualquer atividade sem o acompanhamento de alguém.
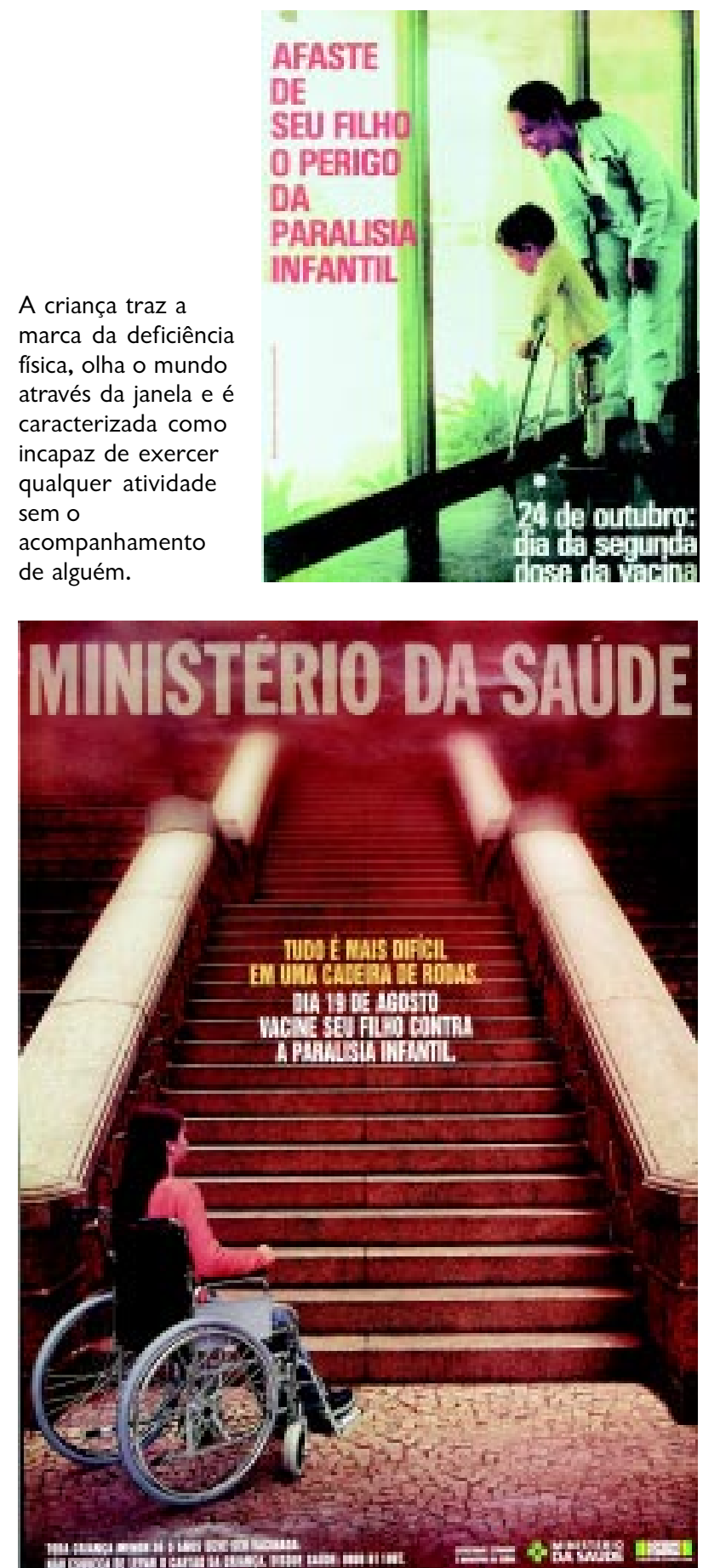

“Tudo é mais difícil em uma cadeira de rodas", mas não é impossível. A mensagem alerta para as dificuldades enfrentadas pelo paralítico em seu dia-a-dia, mas mostra também que não se criam condições para melhorar a qualidade de vida e minorar os sofrimentos e as dificuldades daqueles que foram marcados pela doença.
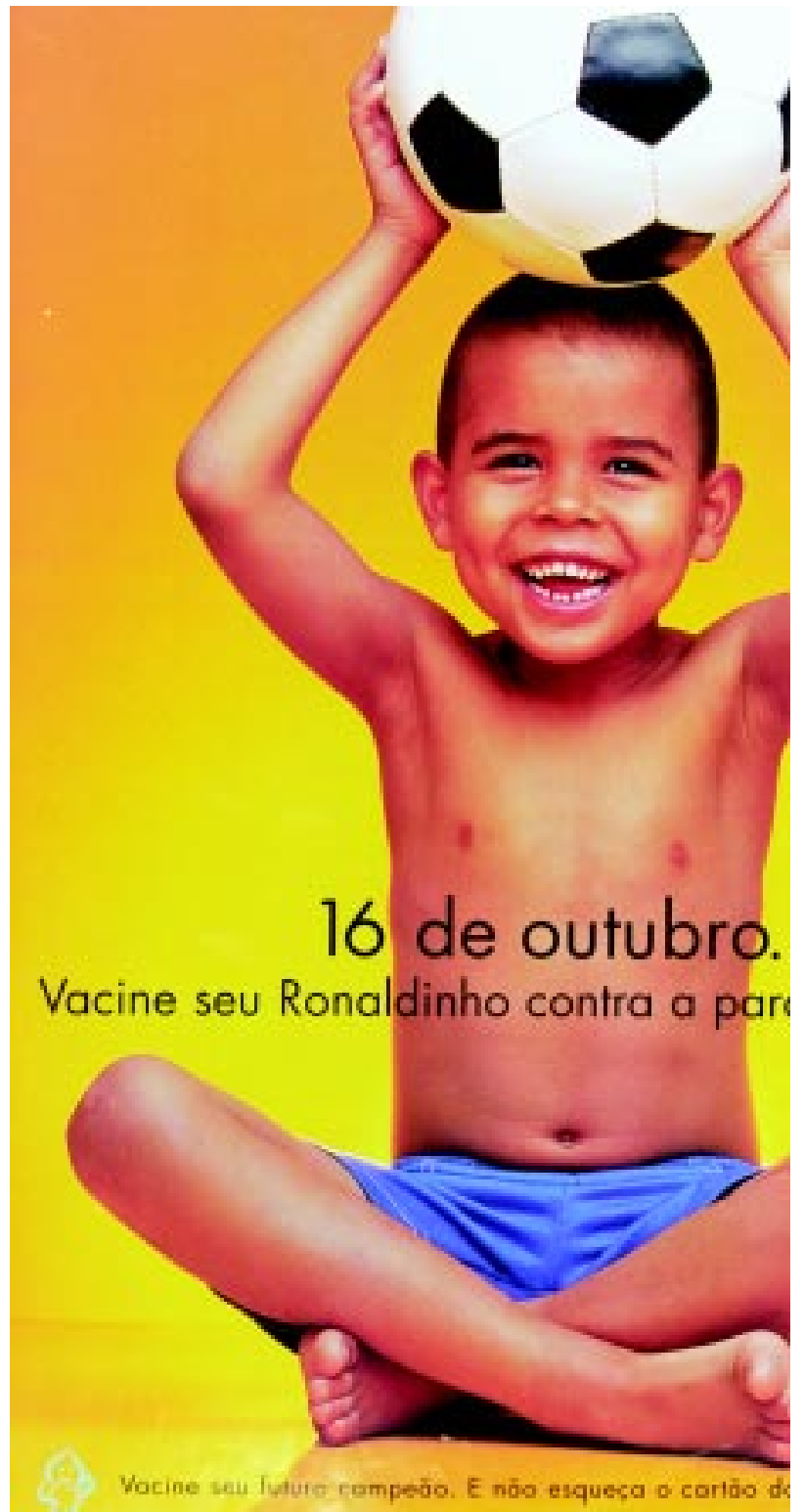

Cartaz da campanha de um dos dias nacionais de vacinação convoca para a segunda dose da vacina Sabin, recorrendo à imagem da versão infantil de um sósia de nossa estrela mundial do futebol. 


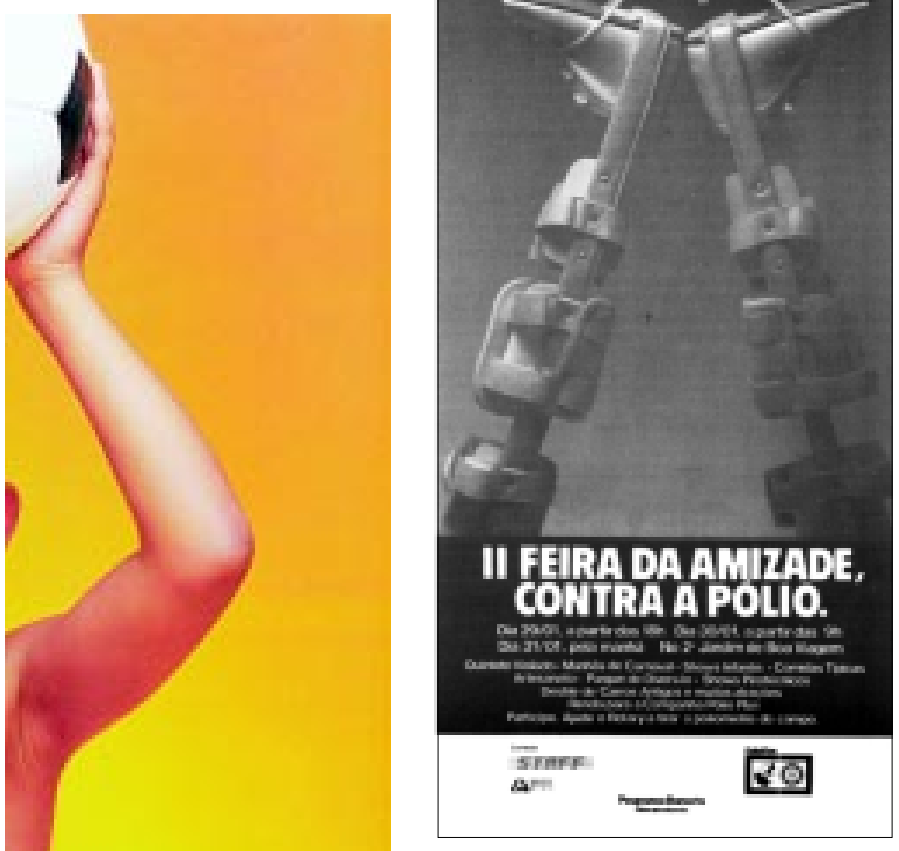

Essa mensagem, apesar de não mostrar o possível "conteúdo" da aparelhagem, é terrível, pois sugere que as pessoas que não tiveram oportunidade de tomar a vacina, só podem fazem uso de "chuteiras especiais".

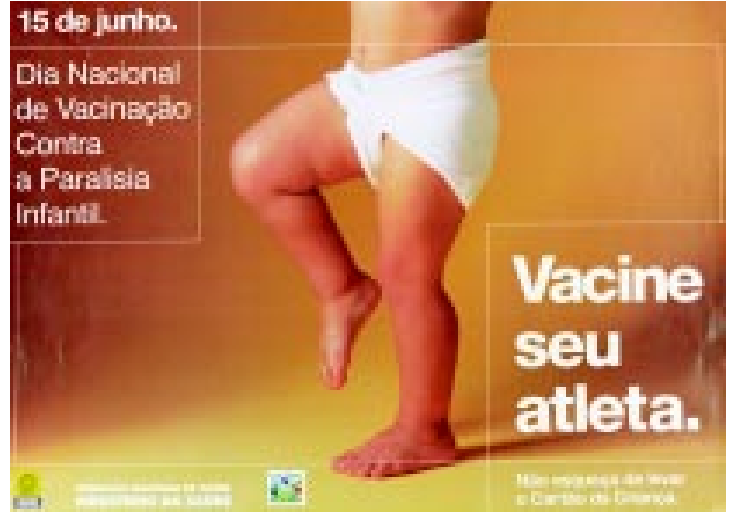

A legenda continua a apelar para essa idéia de incompatibilidade entre deficiência física e sucesso no atletismo.
○.
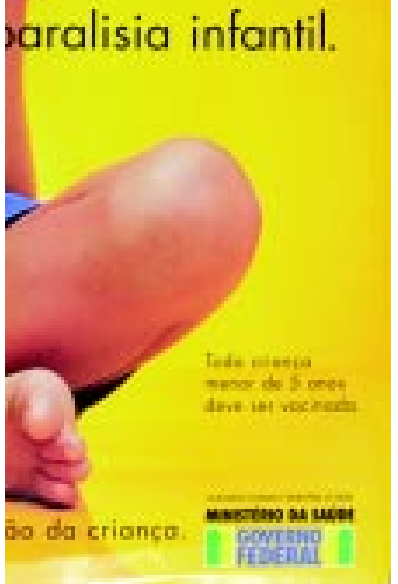

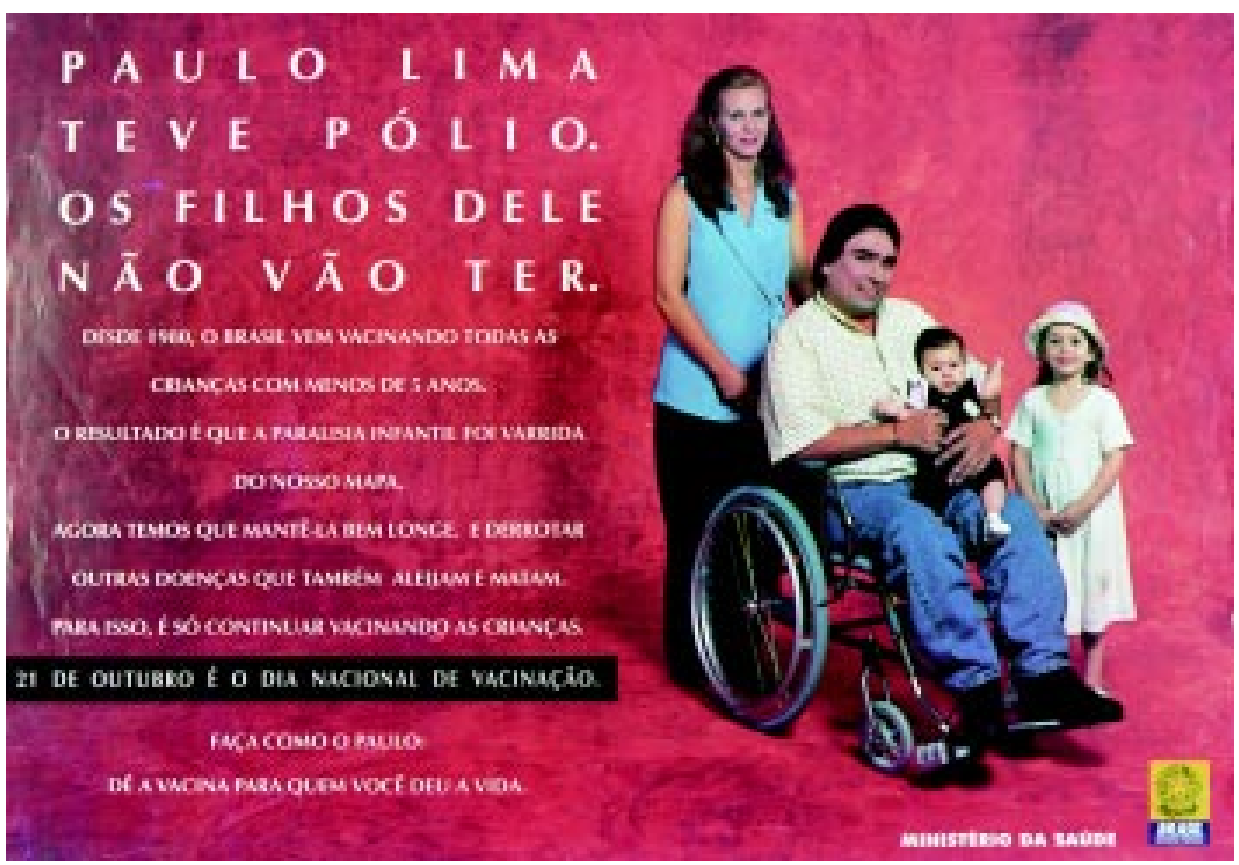

Os dias nacionais de vacinação contra a poliomielite continuam após a erradicação da doença nas Américas, associados a outras vacinas. O objetivo é conscientizar que é necessário continuar vacinando, manter a vigilância sobre a doença e derrotar outras. 
Banner do "Fiocruz pra você", que marca a abertura do DNVs.

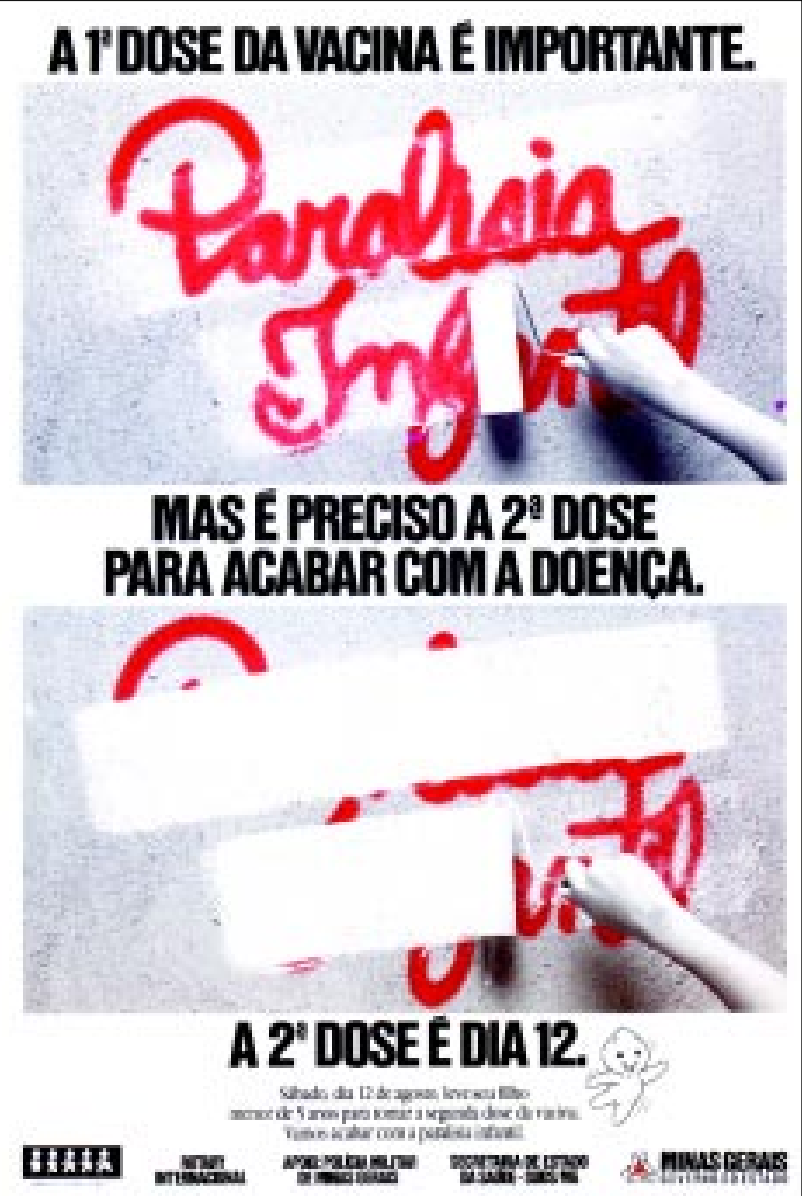

Nesta campanha, não se recorreu mais à imagem da criança associada a um atleta de sucesso nem se fazia uso do terror, mostrando crianças usando aparelhos, cadeira de rodas. Tais imagens foram substituídas pelo apelo à responsabilidade individual.
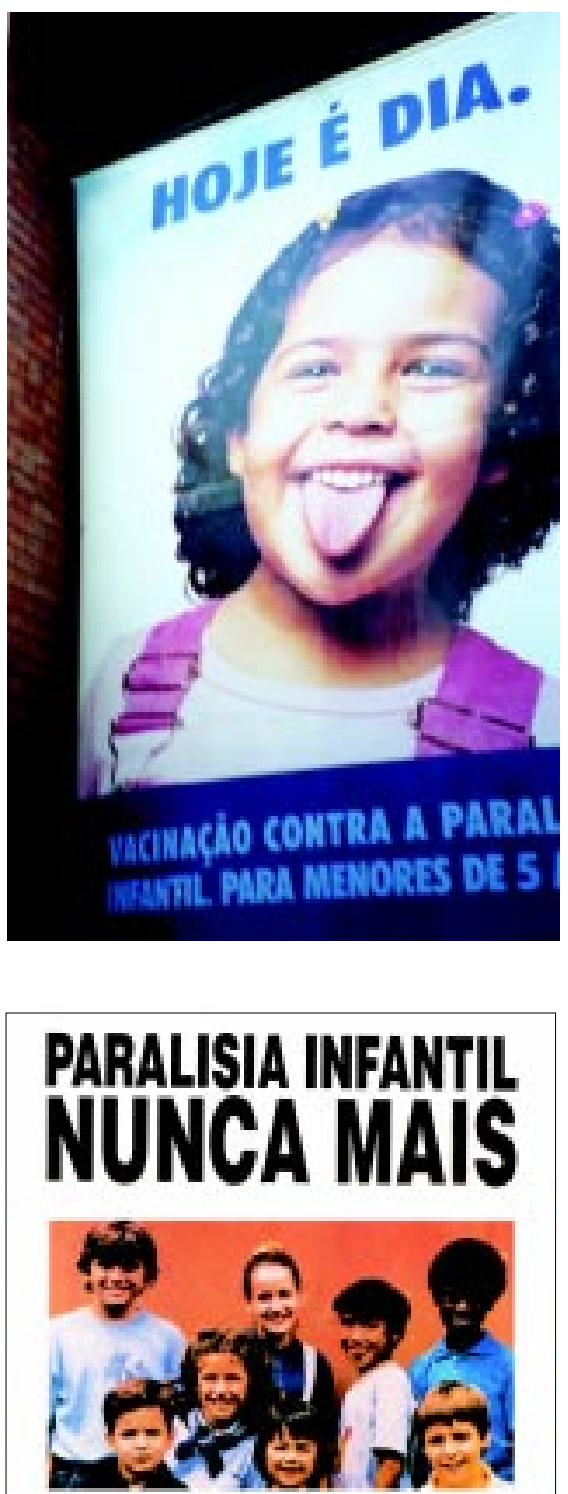

1000 DÓLARES

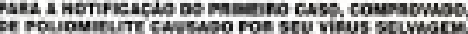

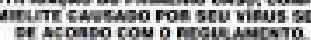

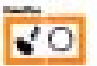

mFoksascoes wos hotant cius

羙 BEMGE

As campanhas mais recentes privilegiam imagens de crianças saudáveis, de diversas etnias, com a proposta de demonstrar que a prevenção é possível para todos. Esta é a ideologia da Organização Mundial de Saúde, difundida pelo slogan 'Por um mundo sem pólio’. 